\title{
Stratospheric nitrogen dioxide in the Antarctic
}

\author{
D. BORTOLI*†t, G. GIOVANELLI $\$$, F. RAVEGNANI \\ and A. PETRITOLI \\ $\uparrow$ Geophysics Centre of Evora (CGE), University of Évora, Rua Romão Ramalho, 59, \\ 7000 Évora, Portugal \\ †Institute of Atmospheric Sciences and Climate (ISAC-CNR), Via Gobetti, 101, 40129 \\ Bologna, Italy \\ §STIL-BAS, Base Observatory, 6000 Stara Zagora, Bulgaria
}

\begin{abstract}
Several UV-visible spectrometers have been developed at the ISAC-CNR Institute. Differential Optical Absorption Spectroscopy (DOAS) methodology is applied to their measurements to monitor the amounts of stratospheric trace gases: mainly ozone $\left(\mathrm{O}_{3}\right)$ and nitrogen dioxide $\left(\mathrm{NO}_{2}\right)$ which is involved in the ozone cycle. Observations of the scattered zenith-sky light were performed with one of these instruments installed at the Terra Nova Bay station (TNB), Antarctica.
\end{abstract}

GASCOD (Gas Analyzer Spectrometer Correlating Optical Differences) is described briefly and a method for data analysis and validation of the results introduced. Some aspects of the DOAS technique are presented: the algorithm allowing the best spectral alignment between spectra obtained with GASCOD and a high-resolution wavelength calibrated spectrum, is explained. Simple considerations allow for calculation of the $\mathrm{NO}_{2}$ concentration in the background spectrum used in DOAS analysis.

For the period of activity of the GASCOD at TNB (1996-2003), the results of $\mathrm{NO}_{2}$ vertical column density (VCD) at twilight show a maximum in the summer and a minimum in the winter. Three years of measurements (2001-2003) are analysed in terms of stratospheric temperature and potential vorticity to obtain information about stratospheric warming that occurred in 2002 over Antarctica. The correlation between $\mathrm{NO}_{2}$ atmospheric content and stratospheric temperature is highlighted. The diurnal variations of $\mathrm{NO}_{2}$, which are controlled by photochemistry, show an unusual behaviour at high latitudes. Analysis of the a.m./p.m. ratios - the sunrise $\mathrm{NO}_{2} \mathrm{VC}$ (a.m.) over the sunset VC (p.m.) - during different seasons and at various Solar Zenith Angles (SZA) is presented and discussed.

\section{Introduction}

Since the identification of stratospheric nitrogen dioxide $\left(\mathrm{NO}_{2}\right)$ as one of the main controllers in ozone-depletion processes (Crutzen 1970, Johnston 1971, Nicolet 1975), the monitoring of its concentration has assumed great importance in the context of ozone variability and climate change. Over the last 30 years understanding of dynamic processes and chemical and photochemical reactions

*Corresponding author. Email: d.bortoli@isac.cnr.it 
involving nitrogen compounds in the stratosphere has improved considerably. The existence of a winter drop in $\mathrm{NO}_{2}$ total column at high latitudes has been explained by the coupling of dynamic and chemical phenomena (Solomon and Garcia 1983). As shown clearly by Noxon et al. (1979), horizontal transport plays a very important role at mid-latitudes: air masses can move very rapidly from high to low latitudes, depending on the weather conditions. Under certain meteorological conditions, this transport process is not as fast and, therefore, the chemistry of NO, $\mathrm{NO}_{2}, \mathrm{~N}_{2} \mathrm{O}_{5}$ and $\mathrm{HNO}_{3}$ may play a predominant role in nitrogen compound partitioning, which follows a change in temperature and insolation time caused by the slow air movement. In fact, stratospheric $\mathrm{NO}_{2}$ shows a diurnal cycle depending on the amount of $\mathrm{N}_{2} \mathrm{O}_{5}$ present and the hours of sunlight during the day. Variations in nitrogen dioxide are controlled mainly by a number of reactions.

$$
\begin{gathered}
\mathrm{N}_{2} \mathrm{O}_{5}+\mathrm{h} v \rightarrow \mathrm{NO}_{2}+\mathrm{NO}_{3} \\
\mathrm{NO}+\mathrm{O}_{3} \rightarrow \mathrm{NO}_{2}+\mathrm{O}_{2} \\
\mathrm{NO}_{2}+\mathrm{O}_{3} \rightarrow \mathrm{NO}_{3}+\mathrm{O}_{2} \\
\mathrm{NO}_{2}+\mathrm{NO}_{3}+\mathrm{M} \rightarrow \mathrm{N}_{2} \mathrm{O}_{5}+\mathrm{M}
\end{gathered}
$$

The relationship between $\mathrm{NO}_{x}$ and $\mathrm{ClO}_{x}$ compounds is better understood: chlorine nitrate $\left(\mathrm{ClONO}_{2}\right)$ is formed by $\mathrm{NO}_{2}$ reacting with $\mathrm{ClO}$, resulting in a longlived reservoir, thus inhibiting the large catalytic ozone depletion potential of chlorine monoxide, as hypothesized by Molina and Rowland (1974). A remaining problem is how chemical processes in high-latitude air masses are connected with mid-latitude ozone chemistry in winter and spring (Proffit et al. 1990, Pierce and Fairlie 1993, Dalberg and Bowman 1994). In order to study the $\mathrm{NO}_{2}$ total column behaviour at mid- and high latitudes, different types of instruments are currently utilized. UV-VIS spectrometers, applying Differential Optical Absorption Spectroscopy (DOAS), are powerful tools in the retrieval of $\mathrm{NO}_{2}$ amounts and they are utilized in ground-based, balloon, airborne and satellite configurations (Sanders et al. 1989, Pfeilsticker and Platt 1994, Oelhaf et al. 1995, Sarkissian et al. 1997).

This work examines observations of the solar light scattered from the zenith sky obtained from one of the ground-based UV-visible systems called GASCOD (Gas Analyzer Spectrometer Correlating Optical Differences) (Evangelisti et al. 1995). The spectrometer was developed at the ISAC-CNR Institute and installed at the Terra Nova Bay (TNB) station, Antarctica $\left(74^{\circ} 26^{\prime} \mathrm{S}, 164^{\circ} 03^{\prime} \mathrm{E}\right)$, during the XII Italian Antarctic Expedition (December 1995). Application of the DOAS technique to measured solar spectra allows retrieval of the nitrogen dioxide content - usually called differential slant column density (DSCD) - along the optical path, depending on the solar elevation. Some of the results obtained in the last few years are presented here, along with a discussion of the problems connected with the DOAS technique. After the presentation of the results obtained during the whole period of activity of GASCOD at the TNB station, the paper focuses on the last three years of measurements to obtain more information regarding the effects caused by the stratospheric warming event which occurred during 2002 in 
Antarctica. Some aspects of the photochemical activity of $\mathrm{NO}_{2}$ will also be explained and discussed.

\section{Methods}

\subsection{Instrumental set-up and measurements}

The GASCOD instruments were developed at the ISAC-CNR Institute (formerly FISBAT) and validated in two NDSC (Network for the Detection of the Stratospheric Changes) campaigns (Hofmann et al. 1995, Roscoe et al. 1999). The equipment consists of a $150 \mathrm{~cm}, \mathrm{f} / 5$ Cassegrain telescope that focuses the incoming radiation onto the entrance slit of the spectrometer. This is composed of a holographic spherical diffraction grating of 1200 grooves $/ \mathrm{mm}$ and a multi-channel detector featuring a 512 metal-oxide semiconductor diode array produced by Hamamatsu. The spectral dispersion is approximately $2.4 \mathrm{~nm} \mathrm{~mm}^{-1}$ (depending on the spectral region investigated) and the typical overall spectral resolution is about $0.5 \mathrm{~nm}$. Band-pass filters are used to reduce the stray light inside the spectrometer. The integration time is selected automatically for each measurement and ranges from seconds at noon to a few minutes at twilight. For long integration times, the dark current is not negligible and, therefore, it is measured after each spectral reading and subtracted from the detected signal. An internal mercury lamp, installed in the Cassegrain telescope, is used for periodic checks of the diffraction grating position, ensuring a spectral accuracy of better than $0.2 \mathrm{~nm}$. An electronic unit drives the spectrometer in the automatic and unattended mode according to predefined measurement cycles, while an external personal computer, connected through an RS232 line, is used to store the recorded spectra. The optical input of the spectrometer points toward the zenith, with a field of view (FOV) of $1.1 \times 10^{-5} \mathrm{sr}$, in order to measure the scattered light in the UV and visible spectral regions. The spectrometer is contained in a thermo-insulated box that ensures constant temperature inside the instrument, avoiding changes in its optical characteristics (e.g. optical dispersion). The instrument is installed in a container near the station, with an 'Optical chimney' used as a window for the incoming radiation and as protection for the spectrometer input. The 'Optical chimney' is composed of two quartz windows enclosing a cylinder of $40 \mathrm{~cm}$ length and $15 \mathrm{~cm}$ diameter (the vacuum in the tube prevents condensation). The outer window is tilted by $45^{\circ}$ in order to prevent snow accumulation on the 'Optical chimney'. Typically, GASCOD instruments installed at the Mt Cimone (Italy) and Stara Zagora (Bulgaria) stations (Petritoli et al. 2002, Werner et al. 2003) carry out measurements only at twilight, when the tracers show maximum absorption mainly due to the longer optical path. The reference spectrum, used for the daily retrieval of the $\mathrm{NO}_{2}$ slant column, is obtained during a short measurement period at approximately noon local time. The GASCOD installed at TNB performs $24 \mathrm{~h}$ measurements. This choice stems mainly from the fact that the station remains unmanned for long periods during the austral winter (March-October).

\subsection{Analysis}

Before processing the raw data with DOAS methodology, the ratio between the signal obtained by the spectrometer during each measurement and its 'exposure' time is calculated to obtain information on the performance of the instrument and the quality of the spectral series measured. This ratio is called the 'Flux Index' (FI). 


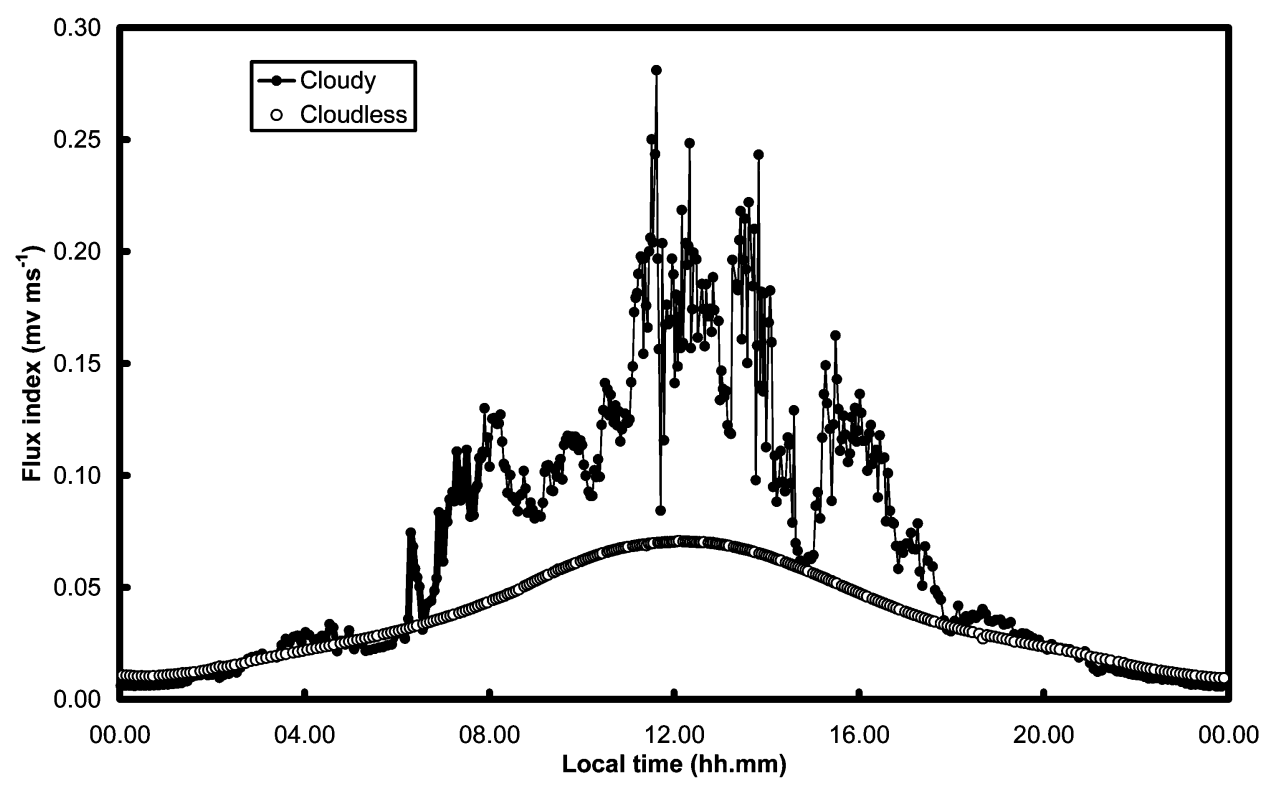

Figure 1. Flux Index - FI - (ratio of the signal obtained by the spectrometer and its 'exposure' time) calculated at Terra Nova Bay station for two days under different meteorological conditions. The FI on 31 January 2001 (cloudless day) presents a regular behaviour, while on 5 February 2001 (cloudy day) more scattered values of FI are obtained.

It provides information on variations in the quantity of the incoming radiation. Figure 1 shows the FI for two days under different meteorological conditions at TNB. During cloud-free days the FI values describe a regular function (figure 1, white circles). If thin layers of clouds are present, the FI can increase by up to four times (figure 1, black circles), due to multiple scattering within the clouds. However, measurements using GASCOD spectrometers are not affected by this increase in radiation flux since the spectral series are carried out by applying the 'auto ranging mode' in order to find the optimal integration time and, hence, achieve a high signal to noise ratio $(\mathrm{S} / \mathrm{N})$. Anomalous behaviour of the FI may occur under very thick cloud conditions or with snow accumulation over the optical chimney of the spectrometer, which causes atypical low FI values. Spectral measurements obtained with the spectrometer are rejected if the corresponding value of FI is lower than the regular function expected (in the case of cloud-free conditions). In fact, the integration time required to obtain the maximum signal established a priori could be greater than the maximum exposure time the instrument is capable of, leading to a low signal to noise ratio.

Figure 2 shows the FI values obtained at local noon during 2001 at the TNB station. The analysis of the FI for 2001 highlights the high percentage of cloudless days (figure 2, black squares) or days with very high and thin clouds (figure 2, grey circles) occurring during that year. Moreover, the FI allows the identification of anomalous behaviour (figure 2, white squares) for some of the days during the austral autumn (26/01 and 05/04), at the beginning of the sunlight period (26/08 and 29/08) and finally for $02 / 09,15 / 09,25 / 10$ and $04 / 11$. The values of the FI are lower than expected, probably due to thick cloud conditions or snow accumulation on the optical chimney, in spite of the inclination of the quartz window installed to protect the GASCOD radiation input. 


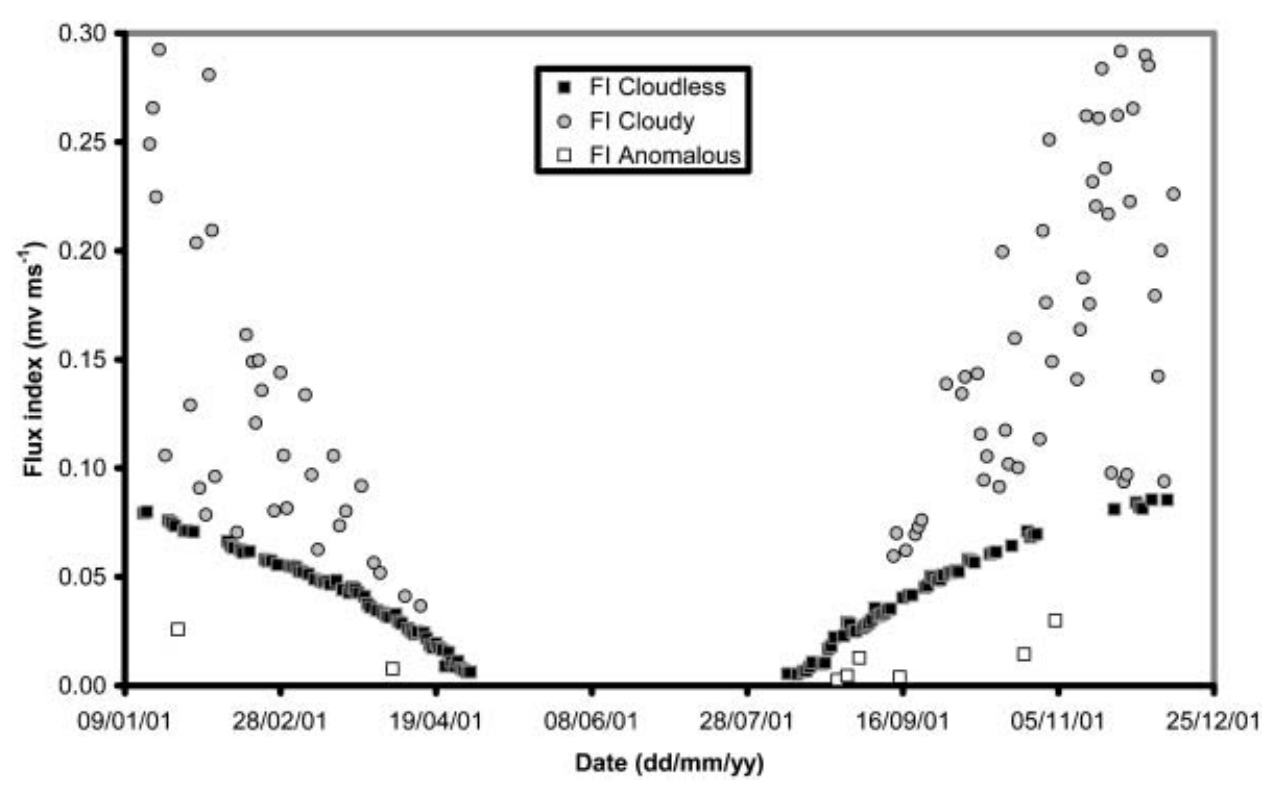

Figure 2. Flux Index obtained at local noon during 2001 at Terra Nova Bay station.

A complete description of DOAS can be found in several references (Noxon et al. 1979, Platt 1994, Elokhov and Gruzdev, 2000). Nevertheless, some aspects of the processing algorithm are discussed below. In order to obtain the absorption structure of the gases under investigation, the Fraunhofer lines of the solar spectra should be removed. The logarithm of the ratio (Log-Ratio) between a reference spectrum $\left(I_{\mathrm{o}}\right)$ and the twilight spectrum $\left(I_{\mathrm{s}}\right)$ is calculated. The low frequency features are removed by applying a low-pass filter operator (hereafter Smooth ()) to the LogRatio spectrum. The difference between Log-Ratio and Smooth (Log-Ratio) is referred to as the 'differential' spectrum. It is compared with the Differential absorption Cross-Sections (DCS) of the gases under investigation, which present measurable absorption features in the selected spectral range (see figure 3 ).

The DOAS algorithm, implemented by the authors, is based on the 'linearization' procedure which builds the new two-dimensional array (wavelength-signal) replacing the measured array expressed as a function of the photodiode position. The linear function dependence on the spectral dispersion in the investigated range allows for the association of each value of the measured spectrum with a wavelength value, considering some spectral features of the Fraunhofer spectrum (IF).

Fish (1994) has already discussed the problem of wavelength calibration. In an attempt to solve this problem for GASCOD observations, the data array, designed as $I_{\mathrm{o}}$, is aligned with the IF, using a similar DOAS procedure (SDP). The SDP results in a solution of the Lambert-Beer law in the Absence of Absorbers (LBAA). In other words the identity $\mathrm{IF}=I_{\mathrm{O}}$ is imposed.

In order to achieve a perfect spectral alignment, the so-called 'shift' and 'stretch' procedures are used. The first one is obtained by a shift of $I_{\mathrm{O}}$ in the wavelength domain until an 'a priori' known spectral position is reached; the second by a variation of the dispersion parameters - by modifying the slope and the intercept of the linear dispersion function obtaining an accordion effect until the best spectral alignment is obtained. The solution of the LBAA is obtained by means of the 


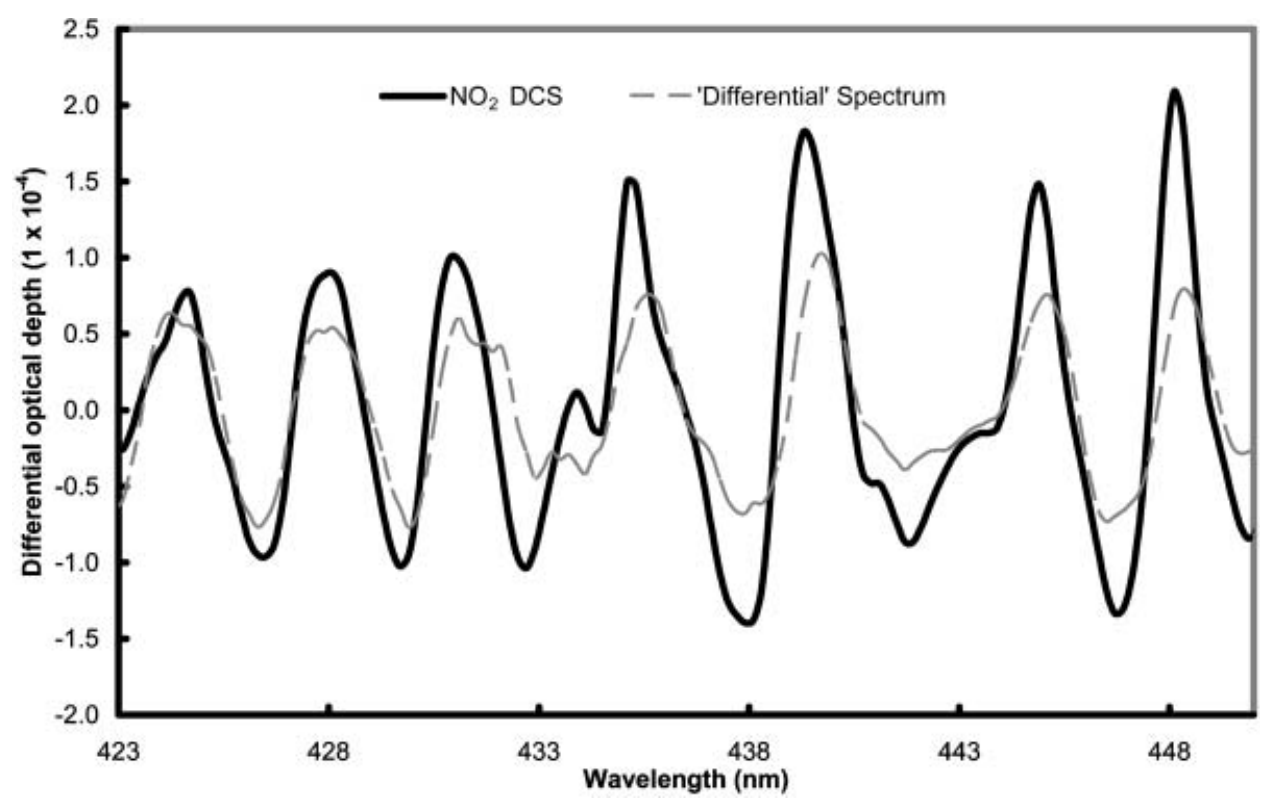

Figure 3. The 'Differential' spectrum (the difference between Log-Ratio and Smooth (LogRatio), where $\operatorname{Smooth}(x)$ is a low-pass filter operator) and the $\mathrm{NO}_{2}$ Differential CrossSection - properly Scaled - are plotted. In the selected spectral range, the differential spectrum features show good agreement with the differential cross-section of nitrogen dioxide, allowing for determination of its atmospheric content.

Singular Value Decomposition (SVD). Marquardt's method is used to minimize the Sum of Square (SOS) of the residual spectrum, using the derivative of the SOS function and modifying the shift and stretch functional parameters. The output of the procedure is the wavelength-calibrated $I_{\mathrm{o}}$ spectrum.

The Lambert-Beer law is applied usually by including the absorbers in the LBAA, and the procedure described above for DOAS processing of all the measured spectra can be used by substituting IF with the calibrated $I_{\mathrm{o}}$, and $I_{\mathrm{o}}$ with the $I_{\mathrm{s}}$ spectra.

Scattering processes and polarization effects can introduce systematic errors in the retrieved amounts. Therefore, additional 'non-absorption' cross-sections such as Mie, Rayleigh, Ring and polarization are introduced in the retrieval algorithm (Chance and Spurr 1997, Kostadinov et al. 1997).

In the past, authors ensured the correct spectral position of the measured spectra through the use of a Calibration Spectrum (CS). As mentioned above, the CS is obtained here by means of a $\mathrm{Hg}$ spectral calibration lamp, before any sky light measurement. If the described alignment procedure is used, the CS becomes unnecessary for wavelength calibration. The spectral lamp measurement can be performed as a periodic check of the grating position and for any changes in spectral dispersion (due, for example, to thermal effects). Thus, the improvement of the DOAS algorithm also allows for a better measurement time resolution.

\section{Reference spectra}

The results of the DOAS data processing - the differential slant column densitiesare differences in trace gas contents, between two spectra measured for different values of Solar Zenith Angles (SZA) and Air Mass Factor (AMF). The $\mathrm{NO}_{2}$ actual 
vertical column density (VCD) is obtained, after adding to the DSCD the reference amount, by dividing the modified slant column (SCD) by the AMF. For small SZAs the AMF can be approximated with the secant of SZA, while for large angles it must be calculated by means of an atmospheric scattering model, which has to represent the real atmospheric conditions as closely as possible (Solomon et al. 1987). Considering the spectral range investigated $(423-460 \mathrm{~nm})$ and assuming the bulk of the $\mathrm{NO}_{2}$ to be located at $25-30 \mathrm{~km}$, for a SZA of $90^{\circ}$ the AMF value is approximately 20. At mid-latitude local noon, it is less than two (Perliski and Solomon 1993). For each day, a spectrum obtained at local noon - the reference spectrum $\left(I_{\mathrm{o}}\right)$ - should be chosen in order to be used as 'background' for analysis of the other measured spectra during the same day. However, to obtain the tracer's seasonal variation, it is preferable to use a single reference spectrum for the processing of all the data collected during the measurement period.

For this purpose a spectrum, obtained with the GASCOD instrument at TNB on 25 December 1998 at local noon $\left(\mathrm{SZA}=51.3^{\circ}\right)$ on a cloudless day, during the 14 th Italian Antarctic Expedition, is used. In this period, during the austral summer, the Sun is always above the horizon (thus $\mathrm{NO}_{2}$ is able to reach photochemical equilibrium) and, assuming transport phenomena to be negligible, the $\mathrm{NO}_{2}$ variation during the day is very low and can be written:

$$
\mathrm{NO}_{2} \mathrm{VCD}_{\mathrm{SZAmin}}=\mathrm{NO}_{2} \mathrm{VCD} \text { SZAmax }
$$

For calculation of the nitrogen dioxide amount in the background spectrum, consider the standard definition of the AMF:

$$
A M F=S / V
$$

where $S$ is the slant column density obtained for the absorber under investigation and $V$ is its vertical column amount. The $\mathrm{NO}_{2} \mathrm{SCD}$, for the highest value of SZA $\left(82^{\circ}\right)$ on the chosen day, was measured. Applying equation (6) both for $51^{\circ}$ and $82^{\circ}$ :

$$
\begin{gathered}
V_{51^{\circ}}=S_{51^{\circ}} / A_{51^{\circ}} \\
V_{82^{\circ}}=\left(S_{82^{\circ}}+S_{51^{\circ}}\right) / A_{82^{\circ}} \\
V_{51^{\circ}}=V_{82^{\circ}}
\end{gathered}
$$

and, consequently,

$$
S_{51^{\circ}}=S_{82^{\circ}} /(\delta-1)
$$

where: $\delta=A_{82} / A_{51}$.

The AMFs are calculated using the AMEFCO model (Atmospheric Model for Enhancement Factor Computation). AMEFCO was developed at ISAC and it is based on the Intensity-weighted Optical Path (IWOP) approach (Slusser et al. 1996). The AMEFCO is a single-scattering model using ray tracing in a spherical twodimensional atmosphere with optical paths integrated over individual shells. Light refraction is not included (Petritoli et al. 1999).

The assumption of constant $\mathrm{NO}_{2}$ values during the day is not strictly valid but the change is only about $10 \%$ (according to a $1 \mathrm{D}$ model computed by integrating a Box Model over all altitudes). From equation(10) a slant column value 
$S_{51^{\circ}}=(4.5 \pm 0.45) \times 10^{+15}$ molecules $\mathrm{cm}^{-2}$ is obtained. This value is used as the background amount that has to be added to the retrieved $\mathrm{NO}_{2} \mathrm{DSCD}$ in order to obtain the $\mathrm{NO}_{2} \mathrm{SCD}$, and this spectrum is adopted as the reference spectrum. To check the processing procedure, the DOAS algorithm is applied to the spectrum chosen as $I_{\mathrm{o}}$, considering it also as the reference spectrum. The retrieved value is equal to $1.2 \times 10^{+11}$ molecules $\mathrm{cm}^{-2}$, a very low amount compared with the typical range for a.m. and p.m. DSCD values $\left(1.0 \times 10^{+16}\right.$ to $1.0 \times 10^{+17}$ molecules $\left.\mathrm{cm}^{-2}\right)$.

\section{Observations and discussions}

All the following results are presented as vertical or total column densities (except for figure 5 where the slant columns (DSCD) are plotted). The $\mathrm{NO}_{2}$ VCDs are calculated by applying to the measured column (SCD, obtained with the DOAS algorithms (Platt 1994)) the AMF computed with the AMEFCO radiative transfer model (Petritoli et al. 1999). The AMF value used is approximately 20. To avoid bias due to the seasonal dependency of the vertical profile and, hence, in the AMF, different boundary conditions are applied to the model with the aim of distinguishing summertime from wintertime air masses. The $\mathrm{NO}_{2} \mathrm{VCD}$ at $90^{\circ}$ of SZA (for sunrise - a.m., and sunset-p.m.) is calculated with a cubic interpolation of the data in the SZA domain, because GASCOD is not able to take measurements at a fixed SZA. The errors associated with the presented results are in the range of 5-8\%. Values with larger errors, due to very low signal intensity, are rejected. In the plots shown in figures 5 to 7 , error bars are omitted for clarity.

\subsection{Seasonal variations}

Figure 4 shows plots of the $\mathrm{NO}_{2} \mathrm{VCD}$ time series obtained at twilight for the whole period of activity of the GASCOD spectrometer at TNB. During the first year of activity (1996) the equipment worked well. In the following years (1997, 1999 and 2000), some hardware and software bugs caused a loss of data for the austral spring season. In 1998 problems occurred with the power supply of the station and prevented data acquisition.

A clear seasonal variation emerges from the results. During the austral autumn (when the Sun starts to descend below the horizon-10/11 February) the $\mathrm{NO}_{2} \mathrm{VCD}$ values decrease from a maximum value of about $5.0 \times 10^{15}$ molecules $\mathrm{cm}^{-2}$ to a minimum (less than $1.0 \times 10^{14}$ molecules $\mathrm{cm}^{-2}$ ), at the beginning of the winter season (when the Sun remains always below the horizon-7/8 May). At the end of the polar night (8/9 August) the nitrogen dioxide total column values increase with a different slope starting from more or less $1.0 \times 10^{14}$ molecules $\mathrm{cm}^{-2}$, to the maximum values at the beginning of the summer season (26/27 October). Both features are due to the well-known processes of lower stratospheric denoxification (conversion of $\mathrm{NO}$ and $\mathrm{NO}_{2}$ into $\mathrm{HNO}_{3}$ ) in the winter season. In other words: the length of daylight strongly affects the $\mathrm{NO}_{2}$ total column values which are also influenced by the stratospheric temperature. The small pre- and post-winter column amounts are the result of gas phase reactions converting $\mathrm{NO}_{2}$ into $\mathrm{N}_{2} \mathrm{O}_{5}$, heterogeneous reactions converting $\mathrm{N}_{2} \mathrm{O}_{5}$ and $\mathrm{ClONO}_{2}$ into $\mathrm{HNO}_{3}$, and possible denitrification (that is sedimentation of $\mathrm{HNO}_{3}$ particles leading to reduced $\mathrm{NO}_{y}$ ). In summer months the lifetime of $\mathrm{HNO}_{3}$ is reduced by photolysis and reactions with $\mathrm{OH}$, both releasing $\mathrm{NO}_{2}$. The results presented are in concordance with the data obtained over the past few years, with similar instrumentation at other Antarctic 


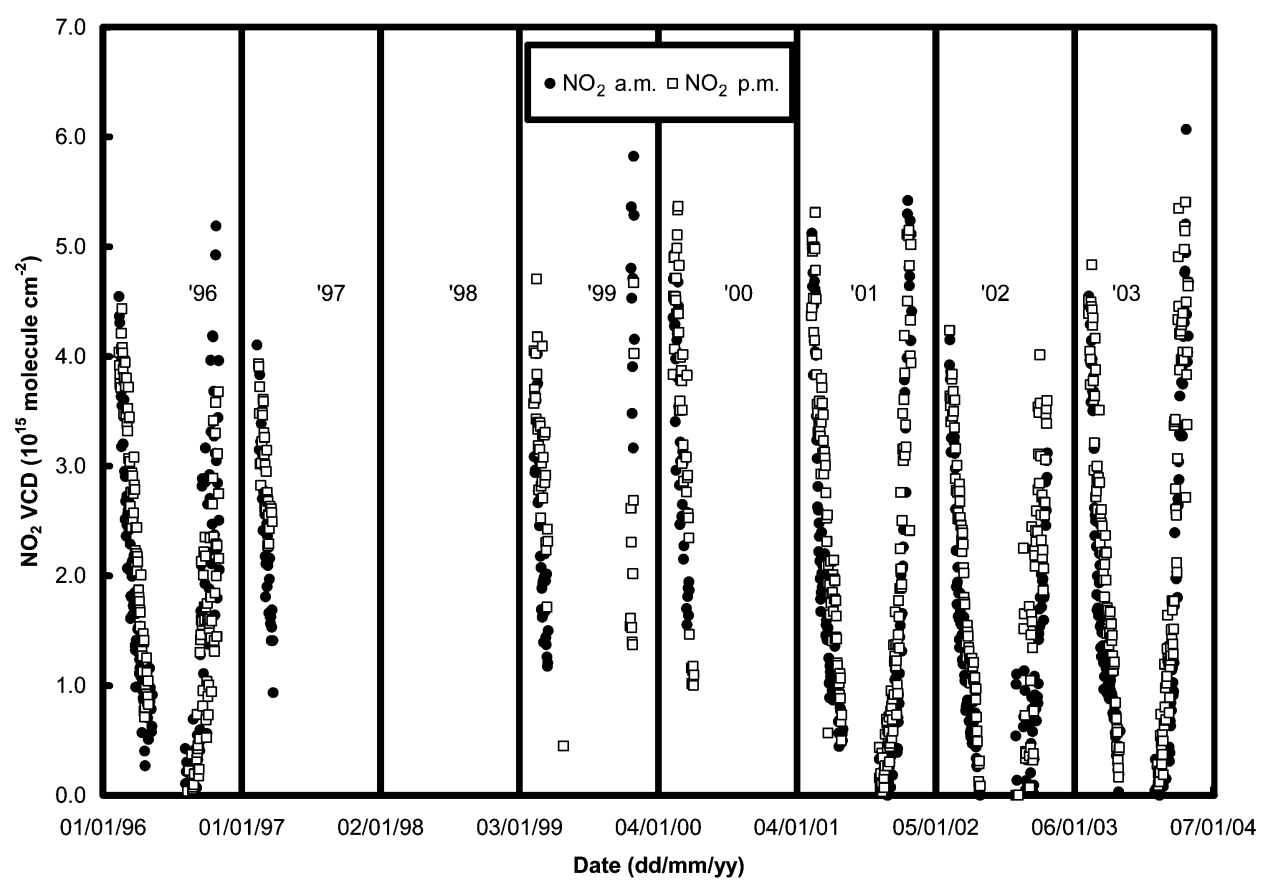

Figure 4. Time series of $\mathrm{NO}_{2}$ VCD measured by GASCOD at Terra Nova Bay station (1996-2003), during morning and evening twilight.

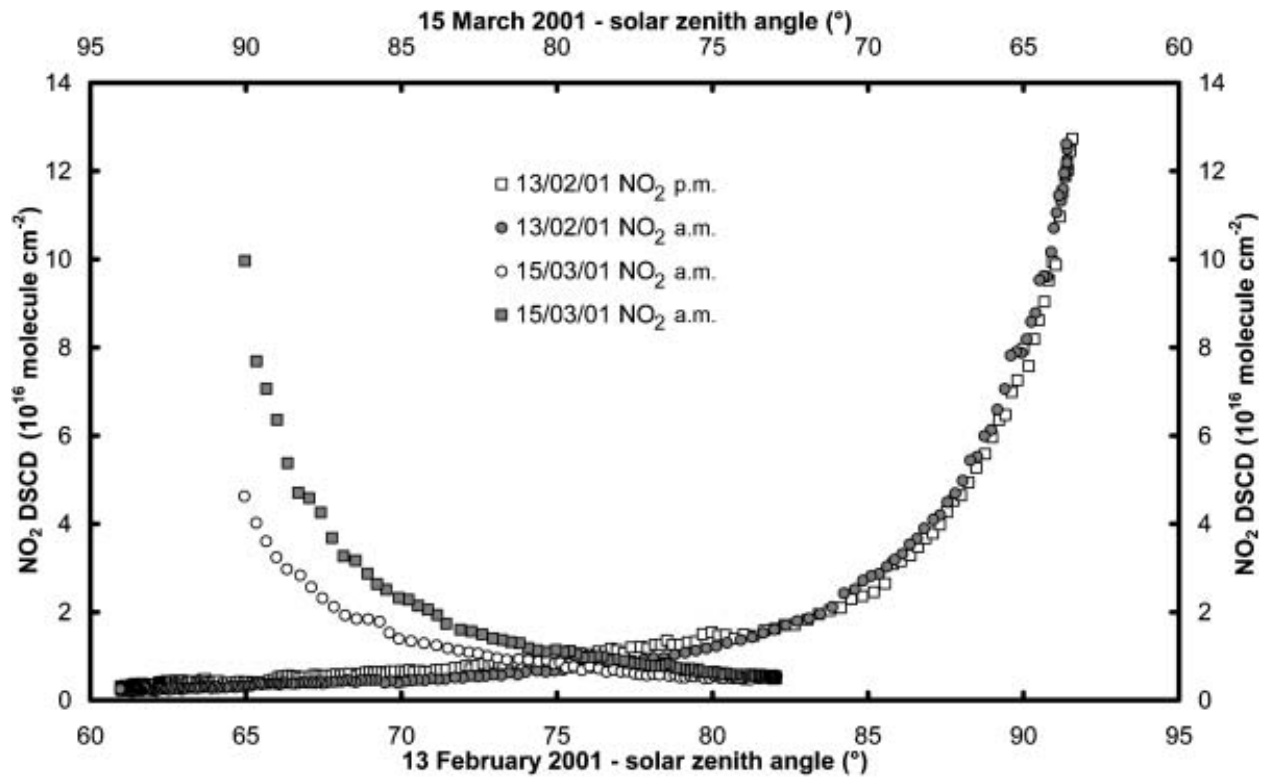

Figure 5. Terra Nova Bay Station, Antarctica. $\mathrm{NO}_{2}$ slant column (DSCD) variations during 13 February 2001 (left and lower axes) and 15 March 2001 (right and upper axes). On 13 February no substantial chemical processes contribute to $\mathrm{NO}_{2}$ diurnal variation a.m. DSCD $\sim$ p.m. DSCD. On 15 March, the decrease in the daylight period causes the deactivation of photochemical reactions. The formation of $\mathrm{N}_{2} \mathrm{O}_{5}$ during the night and its subsequent photolysis during the day lead to greater $\mathrm{NO}_{2}$ DSCDs in the evening twilight than in the morning. 
sites (Pommereau and Goutail 1988, Keys and Johnston 1988, Sanders et al. 1989, Solomon and Keys 1992).

\subsection{Daily variations}

In order to clarify the daily variation of $\mathrm{NO}_{2}$ at high latitudes, the $\mathrm{NO}_{2} \mathrm{DSCD}$ values are plotted as a function of the SZA for two different days in 2001 (figure 5). On 13 February, the $\mathrm{NO}_{2}$ a.m. and p.m. DSCD (figure 5, grey circles and white squares, respectively) are of the same magnitude: this means that no substantial photochemical processes contributed to the $\mathrm{NO}_{2}$ diurnal variation. In fact, the horizon covers the Sun for a few minutes only and, thus, the Earth's shadow cannot reach the altitude of the nitrogen dioxide bulk (about $30 \mathrm{~km}$ ). For this reason, the reactions driving the $\mathrm{NO}_{2}$ to $\mathrm{N}_{2} \mathrm{O}_{5}$ conversion during night-time (equations (3) and (4)) cannot take place. The DSCD behaviour is different for $15 \mathrm{March}$, when the a.m. DSCD (figure 5, white circles) values are systematically lower than the $\mathrm{NO}_{2}$ p.m. DSCD (figure 5, grey squares), due to the deactivation of photochemical reactions caused mainly by the decrease of the daylight period. In fact, the formation of $\mathrm{N}_{2} \mathrm{O}_{5}$ during the night and its subsequent photolysis during the day, lead to greater $\mathrm{NO}_{2}$ DSCD in the evening twilight than in the morning (Noxon et al. 1979). The continuous sunlight in summer inhibits the formation of $\mathrm{N}_{2} \mathrm{O}_{5}$, thus reducing the diurnal variation. In winter there is no daylight to photolyse $\mathrm{N}_{2} \mathrm{O}_{5}$, which similarly reduces the diurnal variation. At the beginning of the winter, the reduction of $\mathrm{NO}_{2}$ takes place when, first, all $\mathrm{NO}_{x}$ is converted to $\mathrm{N}_{2} \mathrm{O}_{5}$ in the absence of light and, later, to $\mathrm{HNO}_{3}$ and then gravitationally eliminated. This can also be observed in figure 4, but the long GASCOD activity period at TNB, prevents a clear view which is possible only by zooming in to certain regions of the plot. The authors have chosen to zoom in to the years 2001, 2002 and 2003 (figures 6(a), (b) and (c), respectively).

During the austral autumn season the shape of the a.m. and p.m. $\mathrm{NO}_{2} \mathrm{VCD}$ values is quite regular in all the presented years of measurements, with the a.m. values systematically lower than the p.m. ones. For the austral spring it is also possible to note some inversions in a.m. and p.m. values and more scattered results, mainly due to the geographical location of TNB which causes the station to be inside the vortex in some periods and outside in others. In this situation, the dynamic effects hide the usual photochemistry described above. Moreover, during the spring season, the ozone is depleted through a number of catalytic reactions in the presence of halogens and light. The $\mathrm{NO}_{2}$ does not react directly with ozone but, as discussed in Kondo et al. (1994), via the chemical reaction $\mathrm{ClO}+\mathrm{NO}_{2}+\mathrm{M} \rightarrow \mathrm{ClONO}_{2}+\mathrm{M}$ and, via heterogeneous reactions on PSCs (Polar Stratospheric Clouds), the $\mathrm{NO}_{2}$ reduces the amount of $\mathrm{ClO}_{x}$ which directly affects $\mathrm{O}_{3}$ depletion.

\subsection{Stratospheric warming during 2002}

Detailed information about the rate of change of $\mathrm{NO}_{2}$ with time can be obtained with Lagrangian observations, which follow an air parcel as a function of time. However, the Eulerian measurements presented here can provide some indications. During 2002, the $\mathrm{NO}_{2}$ VCDs obtained (figure 6(b)) are lower than in 2001 (figure 6(a)) and 2003 (figure 6(c)), but, for 2002 again, the a.m.-p.m. differences are much larger than in other years. This anomalous behaviour can be explained within the framework of the sudden stratospheric warming (SSW) which occurred in the 

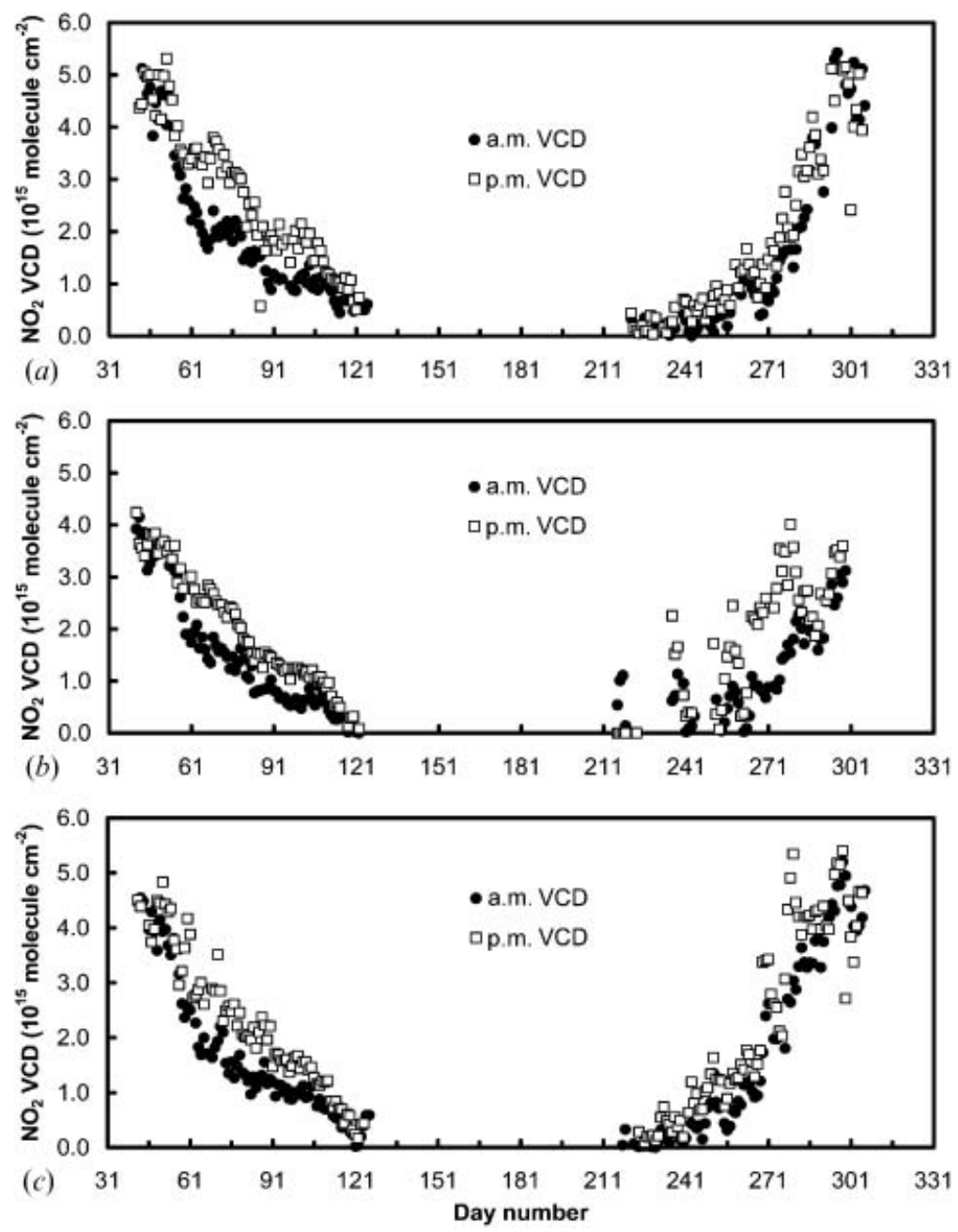

Figure 6. Time series of $\mathrm{NO}_{2}$ VCD for (a) 2001, (b) 2002 and (c) 2003.

Southern Hemisphere during austral spring 2002 (Varotsos 2002, 2003, 2004, Yela et al. 2003). In the following, some atmospheric parameters, such as temperature and potential vorticity over the TNB station, will be analysed together with the results obtained for $\mathrm{NO}_{2} \mathrm{VCD}$.

Figures 7 and 8 are plots of the daily mean of morning and evening twilight $\mathrm{NO}_{2}$ $\operatorname{VCD}(\overline{V C D})$ together with the stratospheric temperature and the potential vorticity, properly scaled, allowing for direct comparison of these quantities. The behaviour of $\overline{V C D}$ time series and stratospheric temperature is quite similar for 2001 and 2003 (figure 7(a), (c)). During the first part of 2002 (figure 7(b)) the behaviour is also similar, but for the austral spring it is possible to note lower values for $\overline{V C D}$ and more scattered data for the temperature, with very high values compared with those for 2001 and 2003. The highest temperatures occurred in August-September and, more precisely, for days 215-218 (3-6 August), 225-228 (13-16 August), 234-239 (22-27 August), 243-249 (31 August-6 September), 255-259 (12-16 September) and 

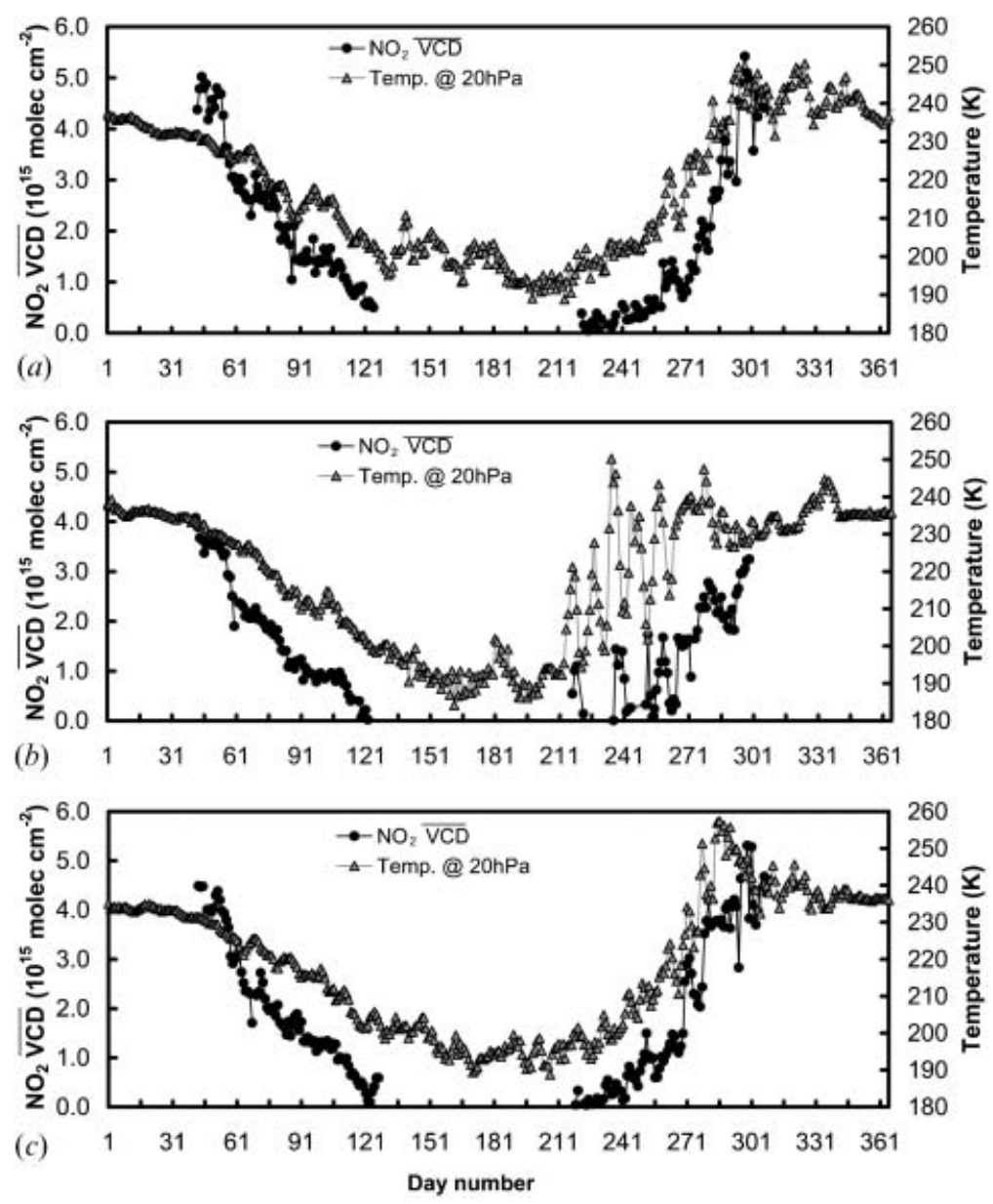

Figure 7. Average of evening and morning twilight observations of $\mathrm{NO}_{2} \operatorname{VCD}(\overline{V C D})$ along with $20 \mathrm{hPa}$ temperatures at Terra Nova Bay station during (a) 2001, (b) 2002 and (c) 2003 .

264-272 (21-26 September). For these days, the temperatures were similar to those observed during the austral summer. As shown by Varotsos (2004), this aspect, together with other dynamic diagnostics, led to the distortion and split of the polar vortex and to its early disappearance. This last factor could give an explanation of the high diurnal variation of $\mathrm{NO}_{2} \mathrm{VCD}$ (figure $6(b)$ ) during spring 2002, providing further evidence of non-denitrified extra vortex air, as the $\mathrm{NO}_{2} \mathrm{VCD}$ a.m. and p.m. were of the same magnitude as those obtained for the autumn at TNB. The good correlation between stratospheric temperature and $\mathrm{NO}_{2} \overline{V C D}$ can be observed also for 2001 and 2003, since each strong variation in the temperature corresponds with a variation in the $\overline{V C D}$. For example, in 2001 (figure $6(a)$ ), the variation of $11 \mathrm{~K}$ from day 259 (16 September with $211 \mathrm{~K}$ ) to day 263 (20 September with $222 \mathrm{~K}$ ) corresponds with an increase in $\mathrm{NO}_{2} \overline{V C D}$ of $0.9 \times 10^{15}$ molecules $\mathrm{cm}^{-2}$ (from 0.5 to $1.4 \times 10^{15}$ molecules $\mathrm{cm}^{-2}$ ). Similarly, in 2003 (figure $6(c)$ ), the difference of $23 \mathrm{~K}$ between day 267 (23 September with 210K) and day 272 (26 September with 233K), 

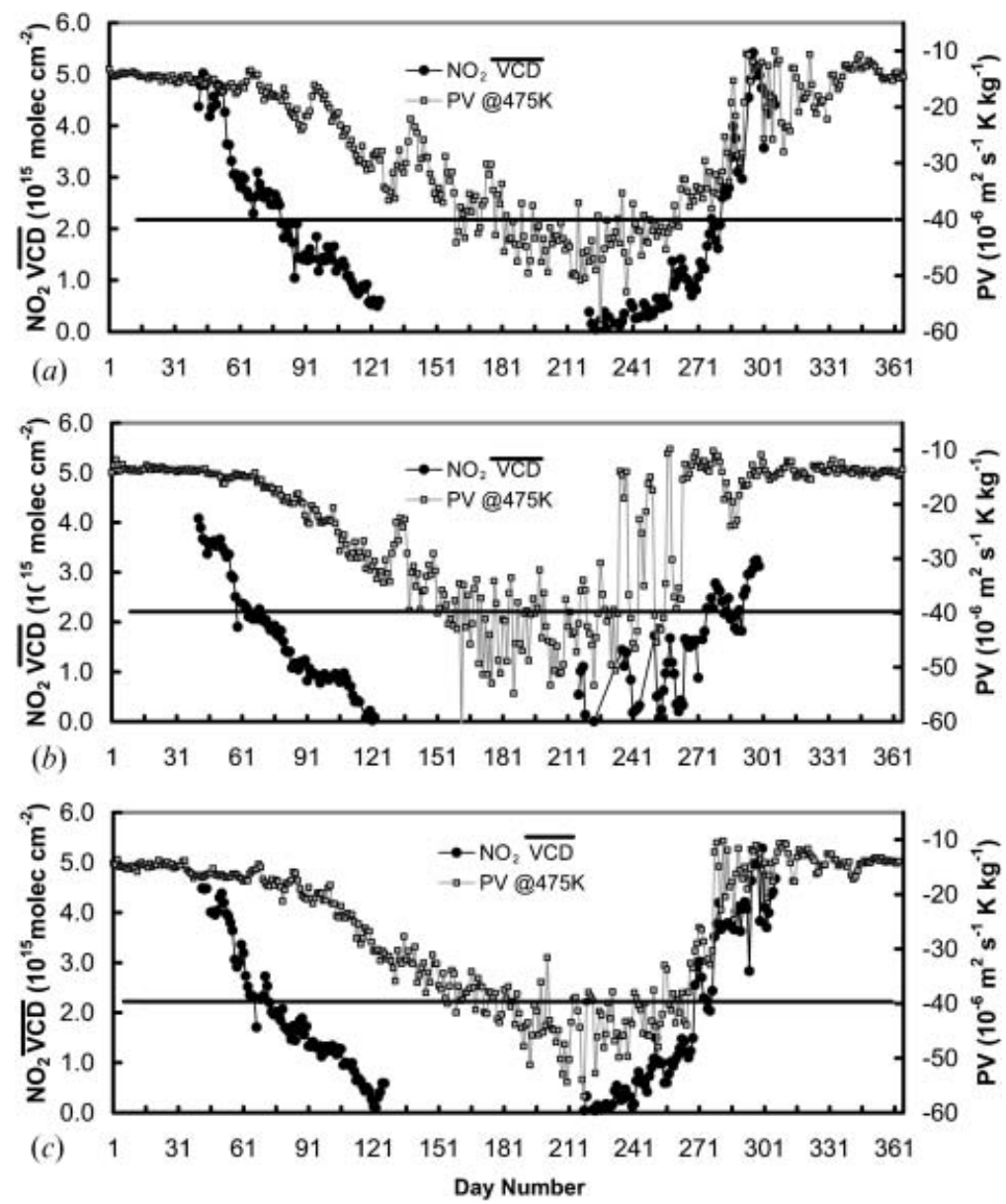

Figure 8. Potential vorticity at $475 \mathrm{~K}$ and average of twilight $\mathrm{NO}_{2} \operatorname{VCD}(\overline{V C D})$ during $(a)$ 2001, (b) 2002 and (c) 2003 at Terra Nova Bay station.

led to an increase in $\mathrm{NO}_{2} \overline{V C D}$ of $2.9 \times 10^{15}$ molecules $\mathrm{cm}^{-2}$ (from 1.1 to $3.0 \times 10^{15}$ molecules $\mathrm{cm}^{-2}$ ).

Analysis of the potential vorticity over TNB (figure $8(a),(b),(c)$ ), is a useful tool for detecting whether the TNB station was inside or outside of the polar vortex. The value of -40 PVU was fixed as the threshold limit. According to that, during 2001 (figure $8(a)$ ), the vortex was over the TNB station for most of the winter and spring seasons. Analysing only the period from day 221 to 263 (9 August, 20 September), it can be seen that the station was outside the vortex for only five days $(225,236,241$, $246,260)$. During the same period in 2003 , the vortex was far away from TNB for a higher number of days than in 2001 (15 days can be identified easily from figure $8(c)$ ). For austral spring 2002 (figure $8(b)$ ), the potential vorticity values are much higher than in 2001 and 2003 and, for day 221 to 263, the station was out of the vortex for most of the time. On day 255 (12 September) TNB was in the vortex for the last time in 2002. For 2001 and 2003 the vortex left the station on days 263 and 266, respectively. Regarding the GASCOD measurements, it can also be noted that when the station is in the vortex the lowest values of $\mathrm{NO}_{2} \mathrm{VCD}$ are obtained. 
The earliest disappearance of the vortex in 2002 over TNB also confirms the occurrence of stratospheric warming in Antarctica.

\section{4 a.m.Ip.m. behaviour}

At high latitudes, the fact that the Sun remains above the horizon for a long period (at TNB about 90 days) involves characteristic a.m./p.m. seasonal variations that are presented in figure 9. It is possible to verify that for polar regions the a.m./p.m. ratio converges to 1 in the summer. In February it begins to decrease until about the end of March and then the ratio increases again until the end of April. After this period, for some days before the beginning of the polar night, the a.m./p.m. ratio decreases again. The reason for this observed behaviour could be caused by the very low values of $\mathrm{NO}_{2} \mathrm{VCD}$ measured, near the detection limit of the instrument. At the beginning of the spring season the a.m./p.m. ratio increases with opposite slope, but occasionally it assumes values greater than 1, revealing an inversion in the normal behaviour of the $\mathrm{NO}_{2}$ amount at sunset and sunrise. Inside the polar vortex, in this period, the largest phenomena of ozone depletion occur, because of chlorine activation events which also cause low concentrations of nitrogen dioxide. As pointed out above, TNB is within the polar vortex only during certain periods, so when it is out of the vortex, the inversion in the a.m./p.m. ratio could be due to the vortex drift to the vertical of TNB, causing advection of ozone-depleted (and denitrified) air masses from the highest latitudes.

Short-term fluctuations of about two weeks in the a.m. and p.m. slant column can also be noted and may be linked to planetary wave transport. Waves are unable to transport trace species deep into the polar vortex, but can erode material from the edge of the vortex (Juckes and McIntyre 1987), so the fluctuations correspond to air masses with high and mid-latitude characteristics, which correspond to viewing alternately air with different a.m./p.m. ratios.

\section{Conclusions}

Some improvements to the DOAS technique have been explained. In particular, an algorithm was presented which allows for the best spectral alignment between a high-resolution wavelength-calibrated spectrum and a measured spectrum, which is then utilized as the reference spectrum in the DOAS methodology. This results in a reduction in the systematic errors that a non-wavelength calibrated reference spectrum could introduce in the slant column value retrieval. Furthermore the algorithm is not specific for the GASCOD instrument, but can be applied to spectral data obtained with any DOAS spectrometer.

A simple technique to estimate the $\mathrm{NO}_{2}$ 'background absorption' in the reference spectrum $\left(I_{\mathrm{o}}\right)$ for polar-based DOAS systems was presented. It is based on simple approximations applicable during the polar summer when the Sun continuously illuminates the stratosphere and $\mathrm{NO}_{2}$ can achieve photochemical equilibrium.

A simple but effective technique to discriminate cloudy days and snow accumulation on the optical input, which does not require additional measurements, was also presented. This technique proved very useful in rejecting 'bad' spectra from data retrieval.

Daily measurements on $\mathrm{NO}_{2} \mathrm{VCD}$ obtained during sunset and sunrise at TNB Antarctic station since 1996 were presented and discussed. 


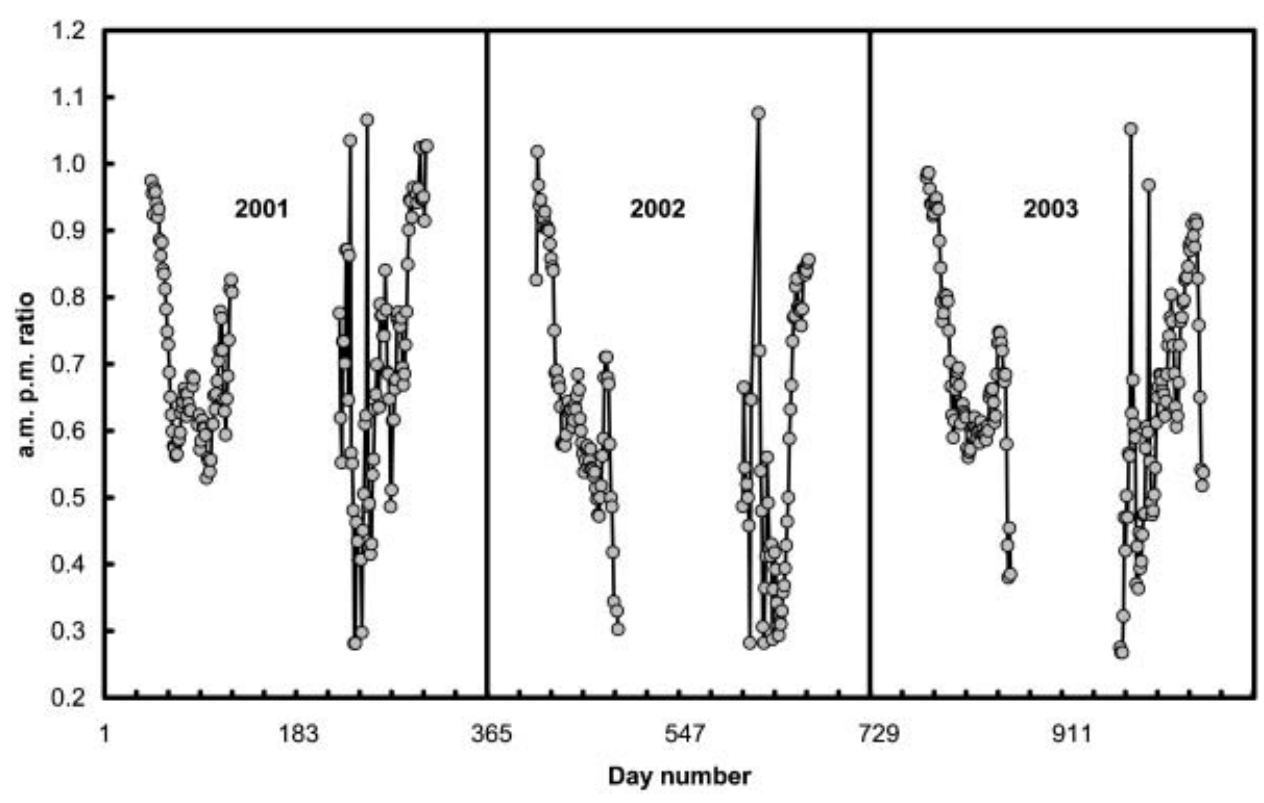

Figure 9. $\mathrm{NO}_{2}$ a.m./p.m. ratio values obtained for Terra Nova Bay station for 2001-2003.

The $\mathrm{NO}_{2}$ VCD seasonal variations shown are obtained by applying the DOAS methodology to measurements of solar zenith scattered radiation. In the Antarctic region the maximum nitrogen dioxide content is reached during summer, while the minimum values are observed in winter, as expected considering the photochemical activity.

The close relationship between $\mathrm{NO}_{2} \mathrm{VCD}$, stratospheric temperature and potential vorticity was highlighted. The high diurnal variation of $\mathrm{NO}_{2} \mathrm{VCD}$, observed during spring 2002, can be explained within the framework of the stratospheric warming phenomena that led to the anticipated extinction of the polar vortex. Moreover, there is evidence of no-denitrified extra vortex air, being the $\mathrm{NO}_{2}$ VCD a.m. and p.m. of the same magnitude as that obtained for the autumn at TNB. Furthermore, the a.m./p.m. ratio behaviour was analysed. In Antarctica the a.m./p.m. ratio converges to 1 during long periods of 'polar day' and 'polar night', as shown clearly for the TNB station. The high latitude spring is characterized as the most chemically and dynamically active period, which explains the great scattering of results retrieved during this season.

\section{Acknowledgements}

The authors would like to thank the reviewer for fruitful comments and suggestions that have improved the paper greatly. The National Antarctic Research Program (PNRA) supported this research. DB was supported financially by the Subprograma Ciência e Tecnologia do $3^{\circ}$ Quadro Comunitário de Apoio. Ivan Kostadinov undertook this work with the support of ICTP - Programme for Training and Research in Italian Laboratories, Trieste, Italy. Many thanks also to Franco Evangelisti, Francescopiero Calzolari and Giuliano Trivellone for their support in Italy and during the Antarctic expeditions. 


\section{References}

Chance, K. and Spurr, R.J.D., 1997, Ring effect studies: Rayleigh scattering, including molecular parameters for rotational Raman scattering, and the Fraunhofer spectrum. Applied Optics, 36, pp. 5224-5230.

CRUtZen, P.J., 1970, The influence of nitrogen oxides in the atmospheric ozone content. Quarterly Journal of the Royal Meteorological Society, 96, pp. 320-325.

DAlberG, S.P. and BowmAn, K.P., 1994, Climatology of large-scale isentropic mixing in the Arctic winter stratosphere from analysed wind. Journal of Geophysical Research, 99, pp. 20 585-20 599.

Elokhov, A.S. and Gruzdev, A.N., 2000, Nitrogen dioxide column content and vertical profile measurements at the Zvenigorod Research Station. Izvestiya Atmospheric And Oceanic Physics, 46, pp. 763-777.

Evangelisti, F., Baroncelli, A., Bonasoni, P., Giovanelli, G. and Ravegnani, F., 1995, Differential optical absorption spectrometer for measurement of tropospheric pollutants. Applied Optics, 34, pp. 2737-2744.

Fish, D.J., 1994, Measurements of stratospheric composition using ultraviolet and visible spectroscopy. PhD thesis, University of Cambridge.

Hofmann, D., Bonasoni, P., De Maziere, M., Evangelisti, F., Giovanelli, G., Goldman, A., Goutail, F., Harder, J., Jakoubek, R., Johnston, P., Kerr, J., McElroy, T., McKenzie, R., Mount, G., Platt, U., Pommereau, J.P., Sarkissian, A., Simon, P., Solomon, S., Stutz, J., Thomas, A., RoOzENDAEL, M.V. and WU, E., 1995, Intercomparison of UV/Visible spectrometers for measurements of stratospheric $\mathrm{NO}_{2}$ for the network for the detection of stratospheric changes. Journal of Geophysical Research, 100, pp. $16765-16791$.

JoHNSTON, J.S., 1971, Reduction of stratospheric ozone by nitrogen oxide catalysis from supersonic transport exhaust. Science, 173, p. 517.

Juckes, M.N. and MCINTYRE, M.E., 1987, A high-resolution one-layer model of breaking planetary waves in the stratosphere. Nature, 328, pp. 590-596.

Keys, J.G. and Johnston, P.V., 1988, Stratospheric $\mathrm{NO}_{2}$ column measurements from three Antarctic sites. Geophysical Research Letters, 15, pp. 898-900.

Kondo, Y., Mathews, A.W., Solomon, S., Koike, M., Hayashi, M., Yamazaki, K., NAKAJIMA, H. and TsuKi, K., 1994, Ground based measurements of column amounts of $\mathrm{NO}_{2}$ over Syowa station, Antarctica. Journal of Geophysical Research, 99, pp. $14535-14548$.

Kostadinov, I., Giovanelli, G., Ravegnani, F., Evangelisti, F., Bonasoni, P., Werner, R. and Bonafè, U., 1997, Polarization and Ring Effect Influences upon Stratospheric DOAS Measurements. Spectroscopic Atmospheric Monitoring Techniques. In Proceedings of EUROPTO 3106, K. Schafer, Proc. EUROPTO 3106; pp. 74-83 (SPIE, Bellingham, WA).

Molina, M.J. and Rowland, F.S., 1974, Stratospheric sink for chlorofluoromethans: chlorine atoms catalysed destruction of ozone. Nature, 249, p. 810.

Nicolet, M., 1975, Stratospheric Ozone: an introduction to its study. Reviews of Geophysics and Space Physics, 13, p. 593.

Noxon, J.F., Whipple, E.C. JR. and Hyde, R.S., 1979, Stratospheric $\mathrm{NO}_{2}$ 1. Observational Method and behaviour at mid latitude. Geophysical Research Letters, 84, pp. 5047-5065.

Oelhaf, H., Wetzel, G., Von Clarmann, T. and Schmidt, M., 1995, Correlative balloon measurements of the vertical distribution of $\mathrm{N}_{2} \mathrm{O}, \mathrm{NO}, \mathrm{NO}_{3}, \mathrm{HNO}_{3}, \mathrm{~N}_{2} \mathrm{O}_{5}, \mathrm{CIONO}_{2}$ and total reactive $\mathrm{NO}_{\mathrm{Y}}$ inside the polar vortex during SESAME. In the Polar Stratospheric Ozone: Proceedings of the 3rd European Workshop, 18-22 September 1995, J.A. Pyle, N.R.P. Harris and T. Amanatinidis (Eds), pp. 187-192, Eur. Comm., Brussels. 
Perliski, L. and Solomon, S., 1993, On the evaluation of air mass factor for near-UV and visible absorption spectroscopy. Journal of Geophysical Research, 98, pp. $10363-10374$.

Petritoli, A., Giovanelli, G., Bonasoni, P., Colombo, T., Evangelisti, F., Bonafe, U., Bortoli, D., Kostadinov, Iv. and Ravegnani, F., 1999, Ground Based $\mathrm{NO}_{2}$ and $\mathrm{O}_{3}$ Analysis at Mt. Cimone Station during 1995-1996: a case study for spring $1995 \mathrm{NO}_{2}$ concentration profile. In Spectroscopic Atmospheric Monitoring Techniques. Proc. EUROPTO 3867, K. Schafer (Ed.), pp. 280-289 (SPIE, Bellingham, WA).

Petritoli, A., Giovanelli, G., Kostadinov, I., Ravegnani, F., Bortoli, D., Gori, C., Bonasoni, P., Evangelisti, F. and Calzolari, F., 2002, Tropospheric and stratospheric NO2 amount deduced by slant column measurements at Mt. Cimone station. Advances in Space Research, 29, pp. 1691-1695.

Pfeilsticker, K. and Platt, U., 1994, Airborne measurements during the Arctic stratospheric experiment: observation of $\mathrm{O}_{3}$ and $\mathrm{NO}_{2}$. Geophysical Research Letters, 21, pp. 1375-1378.

Pierce, R.B. and Fairlie, T.D.A., 1993, Chaotic advection in the stratosphere vortex. Journal of Geophysical Research, 98, pp. 18 589-18 585.

PlatT, U., 1994, Differential optical absorption spectroscopy (DOAS). In Air Monitoring by Spectroscopic Technique, M.W. Sigrist (Ed.), Chemical Analysis Series 127, pp. 27-85 (New York: Wiley).

Pommereau, J.P. and Goutail, F., 1988, Stratospheric $\mathrm{O}_{3}$ and $\mathrm{NO}_{2}$ Observations at the southern polar circle in summer and fall 1988. Geophysical Research Letters, 15, pp. 895-897.

Proffit, M.H., Margitan, J.J., Kelly, K.H., Lowenstein, M. and Poldolske, J.R., 1990, Ozone loss in the Arctic polar vortex inferred from high latitude aircraft measurements. Nature, 347, pp. 31-36.

Roscoe, H.K., Johnston, P., Roozendael, M.V., Richter, A., Roscoe, J., Preston, K.E., Lambert, J.-C., Hermans, C., De Cuyper, W., Dzienus, S., Winterrath, T., Borrows, J., Sarkissian, A., Goutail, F., Pommereau, J.P., D'Almeida, E., Hottier, J., Coureul, C., Didier, R., Pundt, I., Bartlett, L.M., McElroy, T., Kerr, J., Elkhov, Alex, Giovanelli, G., Ravegnani, F., Premuda, M., Kostadinov, I., Erle, F., Wagner, T., Pfeilsticker, K., Kenntner, M., Marquard, L.C., Gil, M., Puentedura, O., Arlander, W., Kastad Hoiskar, B.A., Tellefsen, C.W., Heese, B., Jones, R.L., Aliwell, S.R. and FreshwATER, R.A., 1999, Slant columns measurements of $\mathrm{O}_{3}$ and $\mathrm{NO}_{2}$ during the NDSC intercomparison of zenith-sky UV-visible spectrometers in June 1996. Journal of Atmospheric Chemistry, 32, pp. 281-314.

Sanders, R.W., Solomon, S., Carroll, M.A. and Schmeltekopf, A.L., 1989, Visible and Near-Ultraviolet spectroscopy at McMurdo station, Antarctica. 4. Overview and daily measurements of $\mathrm{NO}_{2}, \mathrm{O}_{3}$ and $\mathrm{OClO}$ during 1987. Journal of Geophysical Research, 94, pp. 11381-11391.

Sarkissian, A., Vaughan, G., Roscoe, H.K., Barlett, L.M., O’Connor, F.M., Drew, D.G., Huges, P.A. and Moore, D.M., 1997, Accuracy of measurements of total ozone by a SAOZ ground-based zenith sky visible spectrometer. Journal of Geophysical Research, 102, pp. 1379-1390.

Slusser, J., Hammond, K., Kylling, A., Stamnes, K., Perliski, L., Dahlback, A., Anderson, D. and Demajistre, R., 1996, Comparison of air mass computations. Journal of Geophysical Research, 101, pp. 9315-9321.

Solomon, S. and Garcia, R., 1983, On the distribution of Nitrogen Dioxide in the High latitude stratosphere. Journal of Geophysical Research, 88, pp. 5229-5239.

Solomon, S. and KeYs, J.G., 1992, Seasonal variations in Antarctic $\mathrm{NO}_{x}$ chemistry. Journal of Geophysical Research, 97, pp. 7971-7978.

Solomon, S., Schmeltekopf, A. and SAnders, R., 1987, On the interpretation of zenith sky absorption measurements. Journal of Geophysical Research, 92, pp. 8311-8319. 
VArotsos, C., 2002, The southern hemisphere ozone hole split in 2002. Environmental Science and Pollution Research, 9, pp. 375-376.

VArotsos, C., 2003, What is the lesson from the unprecedented event over Antarctica in 2002? Environmental Science and Pollution Research, 10, pp. 80-81.

VARotsos, C., 2004, The extraordinary events of the major, sudden stratospheric warming, the diminutive Antarctic ozone hole, and its split in 2002. Environmental Science and Pollution Research, 11, pp. 405-411.

Werner, R., Kostadinov, Iv., Valev, D., Atanasov, At., Giovanelli, G., Ravegnani, F., Petritoli, A. and Bortoli, D., 2003, Spectrometric measurements of $\mathrm{NO}_{2}$ slant column amount at Stara Zagora Station $\left(42^{\circ} \mathrm{N}, 25^{\circ} \mathrm{E}\right)$. Advances in Space Research, 31, pp. 1473-1478.

Yela, M., Parrondo, C., Rodríguez, S., Gil, M., Araujo, J., Ochoa, H., Diaz, S., Deferrari, G. and ReImer, E., 2003, The 2002 Antarctic vortex splitting as observed from visible spectroscopy and ozone soundings. Geophysical Research Abstracts, 5, 09093. 